Check for updates

Cite this: RSC Adv., 2018, 8, 12310

\title{
The investigation of in situ removal of Si substrates for freestanding GaN crystals by HVPE $\uparrow$
}

\author{
Moonsang Lee, (D) $\dot{t}^{\star a}$ Dmitry Mikulik (D) $t^{\mathrm{b}}$ and Sungsoo Park ${ }^{\star c d}$
}

We investigate the etching of a Si substrate in the fabrication process of freestanding GaN crystal grown using a Si by HVPE. Followed by crystal growth, Si etching by vapor $\mathrm{HCl}$ at high temperature results in successful fabrication of the freestanding GaN. Due to the complicated vertical gas flows inside the reactor, careful design of the susceptor was implemented. The unintentional formation of $\mathrm{Si}_{x} \mathrm{~N}_{y}$ thin layer at the backside of the Si substrate after the epitaxial growth, which can cause the decreased etch rate and non-uniform etching of a Si substrate, was successfully prevented by $\mathrm{N}_{2}$ purging during and after the etching of a Si substrate. We believe that this study will guide us to achieve the growth of freestanding GaN over 8-inch diameters in the efficient and practical way.

Received 12th February 2018

Accepted 20th March 2018

DOI: $10.1039 / \mathrm{c} 8 \mathrm{ra01347k}$

rsc.li/rsc-advances intermediate low temperature buffer layer by in situ $\mathrm{NH}_{3}$ treatment of substrate. ${ }^{18}$ All these separation processes require additional step outside of HVPE system thus complicating the fabrication of GaN substrates. Furthermore, several barriers such as wafer size limit and cost restrict the commercial use of HVPE GaN substrates.

Recently, we reported on the high quality freestanding GaN with an etch pit density (EPD) of about $1 \times 10^{6} \mathrm{~cm}^{-2}$ over the 2-inch wafer grown using a Si substrate by chemical etching of substrate material after GaN growth. ${ }^{19,20}$ Even if the EPD of the freestanding GaN crystal obtained using in situ removal of a $\mathrm{Si}$ substrate fall short of EPD for homoepitaxially-grown material $\left(\sim 10^{4} \mathrm{~cm}^{-2}\right)$, its value is comparable to commercial HVPE freestanding GaN grown on $\mathrm{Al}_{2} \mathrm{O}_{3}$ substrates (TDD $\left.<1 \times 10^{7} \mathrm{~cm}^{-2}\right)^{21}$ This technique will allow us to obtain freestanding $\mathrm{GaN}$ wafer with a large scale and low fabrication cost, thus enabling to lead to their successful commercialization. Considering the importance of the growth of freestanding GaN via in situ removal of a Si substrate, the understanding of the Si etching in HVPE should be addressed for successful implementation. In other words, the growth of freestanding GaN using in situ removal of a Si substrate cannot be achieved without complete and uniform etching of substrate material, which can give rise to crack and non-uniform thickness in GaN layers. In this paper, we give insights on the Si etching in the proposed method to grow freestanding GaN from a Si substrate by HVPE.

\section{Experimental}

To realize the growth of freestanding GaN from a Si substrate, home-made vertical type HVPE reactor with $4^{\prime \prime}$ diameter was used as shown in Fig. 1. A 2 inch (111) Si wafer with AlN/ $\mathrm{Al}_{0.4} \mathrm{Ga}_{0.6} \mathrm{~N} / \mathrm{GaN}$ buffer layers grown by metalorganic chemical vapor deposition (MOCVD) was used as a substrate for the 


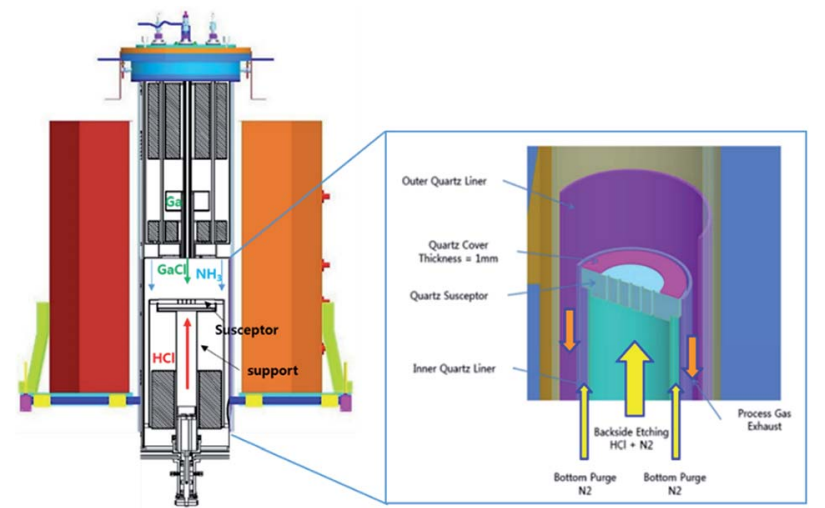

Fig. 1 Schematic diagram of the home-made vertical HVPE reactor and growth/etch zone of the HVPE reactor.

deposition of a thick GaN layer. The growth process is reported elsewhere in details. ${ }^{19,20}$ Briefly, GaN was grown at $1080{ }^{\circ} \mathrm{C}$ in atmosphere pressure with V/III ratio of 20 . The Si etching was performed using $200 \mathrm{sccm} \mathrm{HCl}$ gas flow at $1000{ }^{\circ} \mathrm{C}$ after the growth of a thick GaN layer. The temperature was controlled by a thermocouple passing through resistive heater, which was $5 \mathrm{~cm}$ away from the substrate. $\mathrm{HCl}$ gas diluted with $\mathrm{N}_{2}$ was supplied from the bottom of the reactor through the additional channel. The inset of Fig. 1 illustrates the schematics of the part of wafer-loading zone in the HVPE reactor where the in situ removal of Si substrate was achieved by implementing special quartz parts and susceptor design. $\mathrm{HCl}$ gas can flow through the quartz susceptor from bottom side of the support in HVPE reactor as shown by yellow arrows in Fig. 1b. In addition, we employed $\mathrm{N}_{2}$ purging before and during the etching process to control the Si etching rate and prevent incorporation of GaN growth by-products on the backside of $\mathrm{Si}$ wafer. Without $\mathrm{N}_{2}$ purging after the epitaxial growth, parasitic $\mathrm{Si}_{x} \mathrm{~N}_{y}$ film was formed on the back side of the Si substrate, by which prevented Si etching by HCl. Transmission electron microscopy (TEM) and energy dispersive X-ray spectroscopy (EDX) analysis were used to study the backside of Si wafer.

\section{Results and discussion}

In the chemical etching process, the Si substrate is exposed to $\mathrm{HCl}$ gas flow directed through the quartz susceptor, which has one or multiple holes. The substrate undergoes thermal dry etching and silicon tetrachloride and hydrogen gas form according to the following reaction: ${ }^{22}$

$$
\mathrm{Si}+x \mathrm{HCl}(\mathrm{g}) \rightarrow \mathrm{SiH}_{4-x} \mathrm{Cl}_{x}(\mathrm{~g})+(x-2) \mathrm{H}_{2}(\mathrm{~g})
$$

Previously, we discussed the optimal temperature to etch Si substrate in order to avoid the undesirable tensile stress between the substrate and GaN. ${ }^{1920}$ We found that the maximum in-plane stress can be minimized to $-0.07 \mathrm{MPa}$ at $1000{ }^{\circ} \mathrm{C}$ being slightly compressive and allowing the implementation of Si etching. However, the uniformity of Si etching rate over 2-inch wafer surface is another important factor to obtain crack-free freestanding $\mathrm{GaN}$. The presence of un-etched completely $\mathrm{Si}$ substrate during cooling down can generate micro-cracks and lead to the cracks of the freestanding GaN. To perform complete and uniform etching of Si substrates, rotating susceptors with different shape design were fabricated and tested on Si dummy wafers. Susceptor types 1 and 2 represent multi-openings design and susceptor types 3 and 4 single large opening design, as shown in Fig. $2 \mathrm{a}$. Fig. $2 \mathrm{~b}$ shows the etch rate of Si substrates as a function of wafer positions in different shape of the susceptor with fixed $\mathrm{HCl}$ flow at 200 $\mathrm{sccm}$. It is noticeable that single opening design of susceptors with a larger open area of $\mathrm{Si}$ substrates to $\mathrm{HCl}$ gas flow has better uniformity than the multi-openings susceptor design. Moreover, the highest non-uniformity within the wafer was found at the edges of the wafer. Based on these results, susceptor 4 was used in the experiment with etching Si wafer after GaN deposition in HVPE.

Indeed, the position of Si substrate in susceptor needs to be considered as well during optimization of the etch rate uniformity. Biased position of Si substrate on susceptor can make $\mathrm{HCl}$ gas flow deviation, resulting in etching rate difference. Fig. 3a shows the schematic drawing of Si wafer loaded with the offset to the central position. Note that wide spacing between $\mathrm{Si}$ substrate and susceptor leads the high etch rate of Si substrate near the edge as shown in Fig. 3b. As a result, GaN can be etched/decomposed by high temperature under $\mathrm{HCl}$ ambient. The reaction of HVPE GaN film with the $\mathrm{HCl}$ gas can be expressed as the following decomposition route: ${ }^{23}$

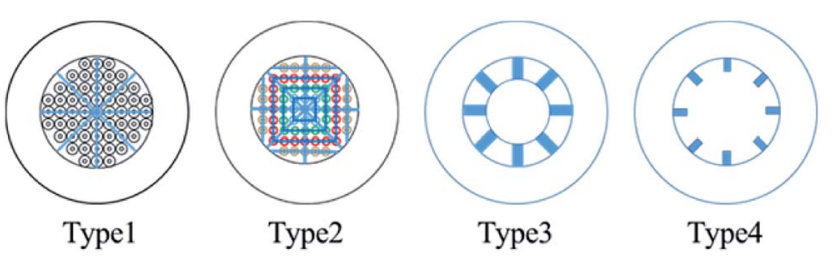

(a)

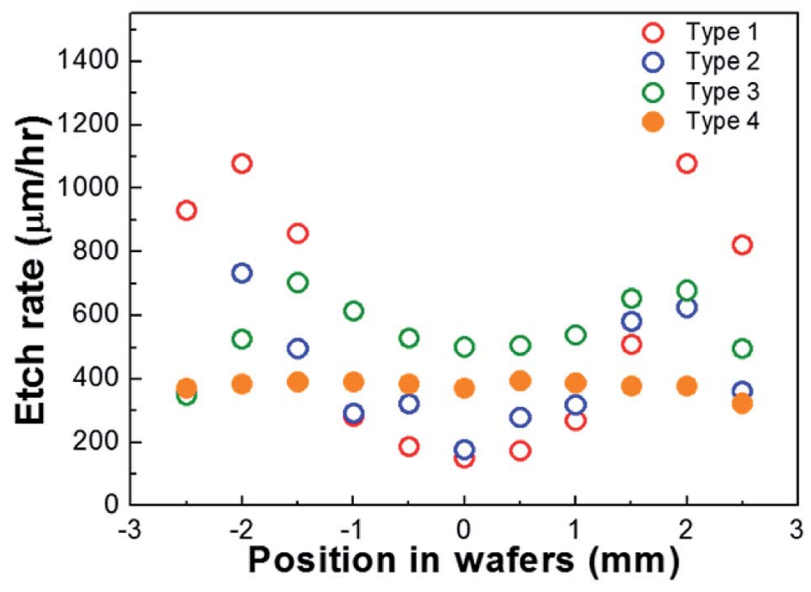

(b)

Fig. 2 (a) Susceptor types used during the etching of Si substrate (b) etch rate uniformity over the Si wafer for different susceptors at fixed $\mathrm{HCl}$ flow $200 \mathrm{sccm}$. 


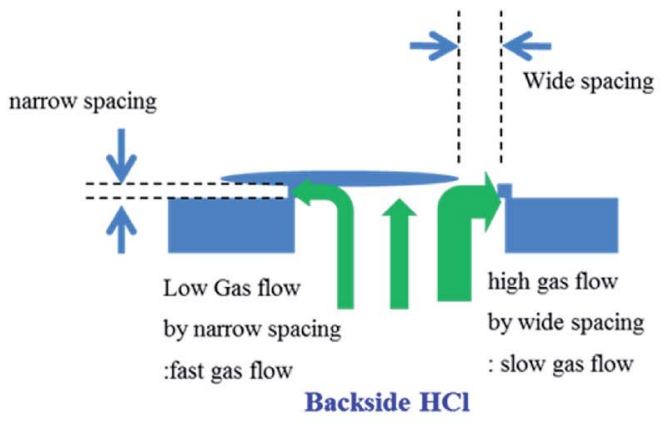

(a)

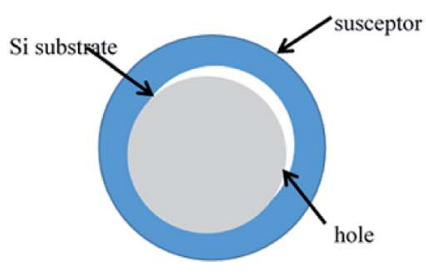

(b)

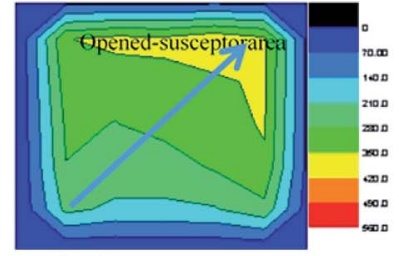

closed susceptor area

Fig. 3 (a) Out of center-loading of a Si substrate on susceptor vs. $\mathrm{HCl}$ flow rate, and (b) etch rate of a Si substrate.

$$
\begin{aligned}
4 \mathrm{GaN}+2 \mathrm{HCl}(\mathrm{g}) \rightarrow 2 \mathrm{Ga}(\mathrm{l}) & +2 \mathrm{GaCl}(\mathrm{g}) \\
& +\mathrm{H}_{2}(\mathrm{~g})+2 \mathrm{~N}_{2}(\mathrm{~g})
\end{aligned}
$$

To clarify the Si removal by the HVPE reactor, we preliminarily tested the etching of Si substrates without growing HVPE GaN. The Si substrates were successfully and uniformly removed with the etch rate of $390 \mu \mathrm{m} \mathrm{h}^{-1}$ by backside $\mathrm{HCl}$ gas with the flow rate of $200 \mathrm{sccm}$ at $1000{ }^{\circ} \mathrm{C}$. However, after growing the HVPE GaN, the Si substrates were not completely etched away when applying even the etch time of $180 \mathrm{~min}$ at the same ambient. This ascribed the unintentional and nonuniform $\mathrm{Si}_{x} \mathrm{~N}_{y}$ deposition on the backside of Si substrates.

During HVPE GaN growth, GaCl and $\mathrm{NH}_{3}$ gas were incorporated into the growth zone in HVPE reactor. The residual $\mathrm{NH}_{3}$ and $\mathrm{HCl}$ species, not reacted during GaN growth, can exist below the growth zone. Therefore, $\mathrm{Si}_{x} \mathrm{~N}_{y}$ can be formed on the backside of Si substrates during or before the Si etch step as follows:

$$
\begin{aligned}
x \mathrm{SiCl}_{4}(\mathrm{~g})+2 \mathrm{H}_{2}(\mathrm{~g}) & +y \mathrm{NH}_{3}(\mathrm{~g}) \rightarrow \mathrm{Si}_{x} \mathrm{~N}_{y} \\
& +4 \mathrm{HCl}(\mathrm{g})+3 / 2 y \mathrm{H}_{2}(\mathrm{~g})
\end{aligned}
$$

To investigate the formation of $\mathrm{Si}_{x} \mathrm{~N}_{y}$ on the back side of the Si wafer, we analyzed the sample with EDX and TEM. Fig. 4a illustrates the cross-sectional TEM image on the backside of $\mathrm{Si}$ substrate after growing HVPE GaN and followed by the removal of Si substrate in HVPE reactor. This clearly shows that undesirable layer was deposited on the backside of a Si substrate during in situ etch process. As shown in Fig. 4b, EDX confirmed the formation of $\mathrm{Si}_{x} \mathrm{~N}_{y}$ on the backside of a Si substrate. From the TEM image, we can conclude amorphous phase of $\operatorname{Si}_{x} \mathrm{~N}_{y}$ with approximately $3 \mathrm{~nm}$ in thickness.

To prevent the deposition of $\mathrm{Si}_{x} \mathrm{~N}_{y}$ on the backside of $\mathrm{Si}$ substrates, the purge step in $\mathrm{N}_{2}$ ambient was added before in situ removal of Si substrates and during HVPE GaN growth in the backside channel, by which the formation of $\mathrm{Si}_{x} \mathrm{~N}_{y}$ was successfully neglected.

Indeed, the flow rate of backside gas, the configuration of susceptors, and the position of Si substrate in susceptors influence on the rate and uniformity of the Si etching. Finally, Si substrates with unintentional $\mathrm{Si}_{x} \mathrm{~N}_{y}$ deposition were etched in 150 min completely.

Finally, a $400 \mu \mathrm{m}$-thick freestanding GaN with 2 inches in diameter was achieved via HVPE growth and in situ removal of

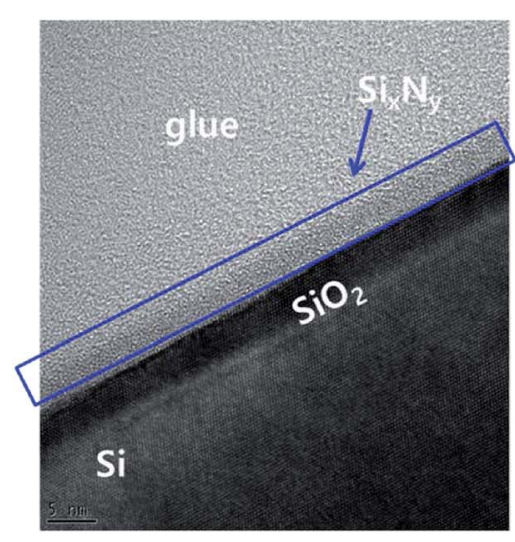

(a)

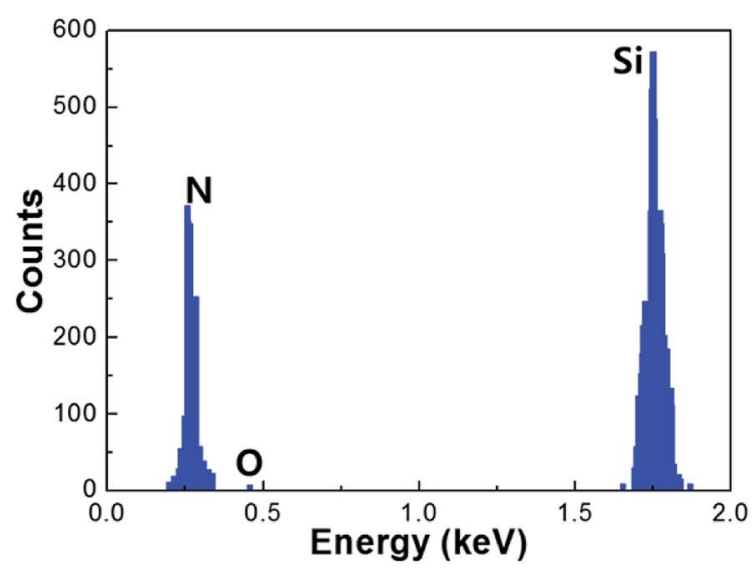

(b)

Fig. 4 (a) Cross-sectional TEM image of the backside on a Si substrate after etching Si substrate in HVPE reactor; (b) EDS data on the backside of a Si substrate after growing GaN and then applying in situ etch of Si substrate in HVPE reactor. 


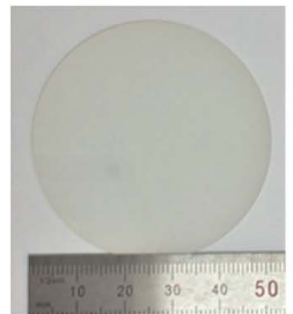

(a)

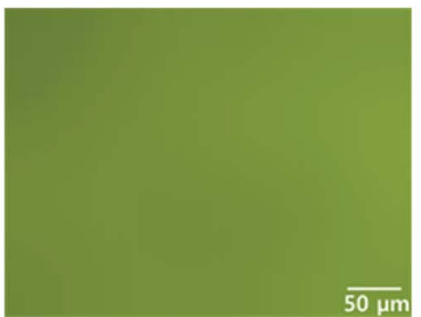

(b)

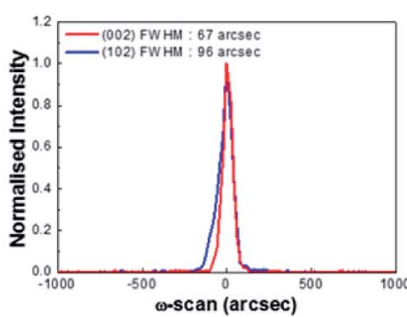

(c)

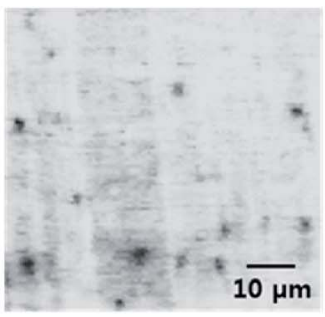

(d)

Fig. 5 (a) A photograph image of a freestanding GaN crystal grown using a Si substrate. (b) Plan-view optical microscopy image of a freestanding GaN crystal grown using a Si substrate. (c) (002) and (102) X-ray rocking curve of freestanding GaN grown via in situ removal of a Si substrate. (d) Micro PL map of a $50 \times 50 \mu \mathrm{m}^{2}$ area of a freestanding GaN crystal with $400 \mu \mathrm{m}$ in thickness grown using in situ removal of a Si substrate. The dark spots represent low PL emission intensity, indicating the dislocation sites.

a Si substrate as shown in Fig. 5a. The surface morphology of asgrown freestanding GaN grown using a Si substrate exhibited the root mean square (RMS) of about $0.37 \mathrm{~nm}$. (See Fig. S2 $\dagger$ ) The shape of freestanding GaN crystals grown from Si substrates was slight concave with the bowing of about $5 \mu \mathrm{m} / 2$ inch, implying the presence of tensile stress in GaN layers. ${ }^{24}$ This is attributed to the difference of defect densities between Ga- and $\mathrm{N}$-faces of the freestanding GaN. ${ }^{25}$ It was estimated to be the FWHM difference of $\sim 130$ arcsec in (002) X-ray rocking curves. Additionally, the wafer bowing of $5 \mu \mathrm{m} / 2$ inch corresponds to the curvature radius of $\sim 60 \mathrm{~m}$. Finally, we can observe that the freestanding GaN was successfully grown from Si substrates without any meltback, pits or cracks as illustrated in Fig. 5b. The values of FWHM for (002) and (102) reflection in X-ray rocking curves were estimated to be 67 arcsec and 96 arcsec, respectively, as shown in Fig. 5c. Furthermore, threading dislocation density of freestanding GaN crystals obtained from in situ removal of a $\mathrm{Si}$ substrate was confirmed by micro-PL mapping, as seen in Fig. 5d. This revealed that the threading dislocation densities were evaluated about $1 \times 10^{6} \mathrm{~cm}^{-2}$.

\section{Conclusions}

During the fabrication of freestanding GaN from Si substrate by HVPE, uniform and complete etching of Si was realized. From prelaminar experiments on Si test wafers, we found the optimal susceptor design with the single large opening.

Loading effect was found detrimental to the fabrication process due to GaN etching/decomposition risk under $\mathrm{HCl}$ ambient at high temperature. Finally, $\mathrm{N}_{2}$ purge step helps to avoid unintentional $\mathrm{Si}_{x} \mathrm{~N}_{y}$ formation on the backside of the $\mathrm{Si}$ wafer, thus preventing Si etching by HCl. We believe that HVPE growth followed by a Si substrate etching will open a new path to obtain freestanding GaN wafer over 8 inches with relatively low defect density.

\section{Conflicts of interest}

There are no conflicts to declare.

\section{Acknowledgements}

This research was supported by Basic Science Research Program through the National Research Foundation of Korea (NRF) funded by the Ministry of Education (2016R1A6A1A03012069).

\section{References}

1 C.-L. Chao, R. Xuan, H.-H. Yen, C.-H. Chiu, Y.-H. Fang, Z.-Y. Li, B.-C. Chen, C.-C. Lin, C.-H. Chiu and Y.-D. Guo, IEEE Photonics Technol. Lett., 2011, 23, 798-800.

2 Y. Kuwahara, T. Fujii, Y. Fujiyama, T. Sugiyama, M. Iwaya, T. Takeuchi, S. Kamiyama, I. Akasaki and H. Amano, Appl. Phys. Express, 2010, 3, 111001.

3 M. Maier, K. Köhler, M. Kunzer, J. Wiegert, S. Liu, U. Kaufmann and J. Wagner, Phys. Status Solidi C, 2008, 5, 2133-2135.

4 D. J. Meyer, D. A. Deen, D. F. Storm, M. G. Ancona, D. S. Katzer, R. Bass, J. A. Roussos, B. P. Downey, S. C. Binari and T. Gougousi, IEEE Electron Device Lett., 2013, 34, 199-201.

5 Z. Vashaei, E. Cicek, C. Bayram, R. McClintock and M. Razeghi, Appl. Phys. Lett., 2010, 96, 201908.

6 J. Freitas Jr, J. Culbertson, N. Mahadik, T. Sochacki, M. Bockowski and M. Iwinska, Cryst. Growth Des., 2015, 15, 4837-4842.

7 B. Sadovyi, A. Nikolenko, J. Weyher, I. Grzegory, I. Dziecielewski, M. Sarzynski, V. Strelchuk, B. Tsykaniuk, O. Belyaev and I. Petrusha, J. Cryst. Growth, 2016, 449, 35-42.

8 Q. Bao, T. Hashimoto, F. Sato, K. Hazu, M. Saito, Y. Kagamitani, T. Ishinabe, R. Kayano, D. Tomida and K. Qiao, CrystEngComm, 2013, 15, 5382-5386.

9 S. Takeuchi, H. Asazu, M. Imanishi, Y. Nakamura, M. Imade, Y. Mori and A. Sakai, J. Appl. Phys., 2015, 118, 245306.

10 E. Richter, M. Gründer, B. Schineller, F. Brunner, U. Zeimer, C. Netzel, M. Weyers and G. Tränkle, Phys. Status Solidi C, 2011, 8, 1450-1454.

11 M. Weyers, E. Richter, C. Hennig, S. Hagedorn, T. Wernicke and G. Tränkle, Light-emitting diodes: research, manufacturing, and applications XII, Proc. SPIE, 2008, 6910, 691001. 
12 M. K. Kelly, R. P. Vaudo, V. M. Phanse, L. Görgens, O. Ambacher and M. Stutzmann, Jpn. J. Appl. Phys., 1999, 38, L217.

13 C. R. Miskys, M. K. Kelly, O. Ambacher and M. Stutzmann, Phys. Status Solidi C, 2003, 1627-1650.

14 K. Motoki, T. Okahisa, N. Matsumoto, M. Matsushima, H. Kimura, H. Kasai, K. Takemoto, K. Uematsu, T. Hirano and M. Nakayama, Jpn. J. Appl. Phys., 2001, 40, L140.

15 T. Nakamura and K. Motoki, Proc. IEEE, 2013, 101, 22212228.

16 E. Richter, C. Hennig, L. Wang, U. Zeimer, M. Weyers and G. Tränkle, Phys. Status Solidi C, 2007, 4, 2277-2280.

17 A. Wakahara, Hydride Vapor Phase Epitaxy of GaN on $\mathrm{NdGaO}_{3}$ Substrate and Realization of Freestanding GaN Wafers with 2-inch Scale, Jpn. J. Appl. Phys., 2000, 39, 2399.

18 K. Kachel, M. Korytov, D. Gogova, Z. Galazka, M. Albrecht, R. Zwierz, D. Siche, S. Golka, A. Kwasniewski and M. Schmidbauer, CrystEngComm, 2012, 14, 8536-8540.
19 M. Lee, D. Mikulik, J. Kim, Y. Tak, J. Kim, M. Shim, Y. Park, U. Chung, E. Yoon and S. Park, Appl. Phys. Express, 2013, 6, 125502.

20 M. Lee, D. Mikulik, M. Yang and S. Park, Sci. Rep., 2017, 7, 8587.

21 T. Sochacki, M. Amilusik, M. Fijalkowski, M. Iwinska, B. Lucznik, J. L. Weyher, G. Kamler, R. Kucharski, I. Grzegory and M. Bockowski, Phys. Status Solidi B, 2015, 252, 1172-1179.

22 S. Noda, K. Tanabe, T. Yahiro, T. Osawa and H. Komiyama, J. Electrochem. Soc., 2004, 151, C399-C404.

23 M. Mastro, O. Kryliouk, M. Reed, T. Anderson, A. Davydov and A. Shapiro, Phys. Status Solidi A, 2001, 188, 467-471.

24 H. Liu, S. Dolmanan, L. Zhang, S. Chua, D. Chi, M. Heuken and S. Tripathy, J. Appl. Phys., 2013, 113, 023510.

25 S. S. Park, I.-W. Park and S. H. Choh, Jpn. J. Appl. Phys., 2000, 39, L1141. 